Journal of Advanced Research in Fluid Mechanics and Thermal Sciences

\title{
An Essential Studies on Tribology's: A Short Review
}

\author{
Norazlianie Sazali ${ }^{1,2,}{ }^{*}$, Ahmad Shahir Jamaludin ${ }^{3}$, Nor Hasrul Akhmal Ngadiman ${ }^{4}$ \\ Faculty of Mechanical \& Automotive Technology Engineering, Universiti Malaysia Pahang, 26600 Pekan, Pahang, Malaysia \\ 2 Centre of Excellence for Advanced Research in Fluid Flow (CARIFF), Universiti Malaysia Pahang, Lebuhraya Tun Razak, 26300 Gambang, \\ Kuantan, Pahang, Malaysia \\ 3 Faculty of Manufacturing and Mechatronic Engineering Technology, Universiti Malaysia Pahang, 26600 Pekan, Pahang, Malaysia \\ 4 School of Mechanical Engineering, Faculty of Engineering, Universiti Teknologi Malaysia, 81310 Skudai, Johor Darul Takzim, Malaysia
}

\section{ARTICLE INFO}

\section{Article history:}

Received 4 December 2019 Received in revised form 13 March 2020

Accepted 15 March 2020

Available online 8 June 2020

Keywords:

Tribology; friction; lubrication; wear; environmental sustainability

\section{ABSTRACT}

\begin{abstract}
Recently, there are a few major malfunctions of machinery and plant have been reported because of their weariness and related reasons, and a few of them causing a great financial loss. It is believed that these continuous failures lead to more serious breakdowns of the machinery and expensive. This is closely related to the tribology, in which tribology is the science and engineering that encompasses how interrelating surfaces behave in comparative motion in natural and artificial systems. It is incorporating the research and use of the values of wear, lubrication also friction.
\end{abstract}

Copyright $@ 2020$ PENERBIT AKADEMIA BARU - All rights reserved

\section{Introduction}

Friction has been engaged in human activities since ancient times. Because of friction, we can stand, run, swim or even putting up a flame. However, while friction is helpful and fundamental for some human exercises, it can likewise make numerous innovative issues. Friction happens in every single mechanical application. These can incorporate a course, slowing mechanisms and transmissions that include two cooperating surfaces, bringing about vitality misfortune and wear. Humankind has consequently endeavoured to overcome the negative impacts of friction during the entire of humankind's history [1-3]. There is an understanding stated that lubrication could lower friction. Lubrication includes setting alternative material, for example, liquid fluid like water and oil between the surfaces to extend the machine or systems cycle life. During the early 1960s, the innovation and science regarding friction, lubrication, and wear were brought together under control named "tribology" [3]. Additional tribology research ended up conceivable with the growth of the Atomic Force Microscope (AFM) in the year 1986 and focused on the small-scale touch of mechanics that built up bond and malfunction severities.

\footnotetext{
* Corresponding author.

E-mail address: azlianie@ump.edu.my (Norazlianie Sazali)
}

https://doi.org/10.37934/arfmts.72.1.18 
This methodology empowers experts to explore friction on the nuclear scale. In this way, analysts can decide how friction elements alter on a naturally noticeable scale under different operating circumstances. Miniaturized scale tribology and nano-tribology have been presented as of late. A three-dimensional standard for the simulation of tribology consists of few lubricant films atomic layers between two substrates (top and bottom) as shown in Figure 1. Each substratum comprises of two layers in contact with the lubricant, the deformable substrate layer and the rigid layer. The space between the substrates is filled by the lubricant atoms. The substrate consists of fixed bottom rigid layer, whereas the top substrate of rigid layer may move due to applied forces [4]. Frictional connections in infinitesimally little segments are critical to the improvement of new items in contemporary innovation, for example, gadgets, sciences, chemistry, and microelectronics [5].

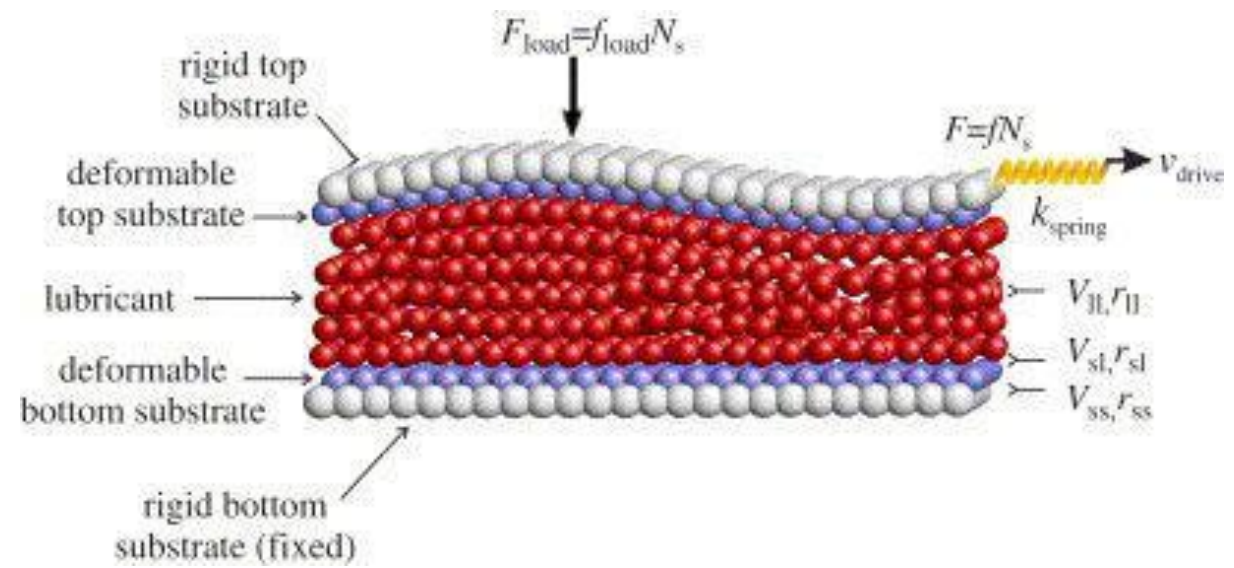

Fig. 1. The MD friction simulation model

\section{Friction and Lubrication}

Friction, the most key wonder going with sliding development of strong bodies, is characterized as the strength of the relative horizontal (unrelated) movement of powerful surfaces, liquid layers, or materials in touch with each other. Friction is divided into a number of types:

i. Dry friction opposes the movement between two strong bodies in touch. Dry friction is categorized into dynamic and static friction (also sliding and kinetic friction).

ii. Internal friction occurs at the point in which the opposing power exists because of development in the parts of a strong body when the body is distorted.

iii. Lubricated or fluid friction occurs if there is any type of lubricant isolated two strong sliding bodies.

iv. Skin friction occurs when dragging any type of solid through any lubricant.

A way to decrease unwanted impact of friction by setting an ointment (lubricant), for example, oil, grease or water, in between reaching surfaces is discovered for quite a long time. If the lubricant between the two interfacing surfaces is unlikely, it enables a considerable decrease of the friction coefficient and the friction force [6-9]. Dr. Robert $\mathrm{H}$. Thurston at the Stevens Institute of Technology (USA) has conducted few studies on the association between friction and lubricant in the early 1870 s and followed by Professor Adolf Martens in the year 1885 [10]. The examination was subsequently resolved at the Royal Prussian Technical Testing Institute in Germany by Professor Richard Stribeck (1861-1950). From the results obtained by Professor Stribeck in the mid-1920s as supposed in "Stribeck" curves, sliding lubricated body friction systems were recognized to be boundary friction, static friction, hydrodynamic friction, and mixed friction. The curve "Stribeck" is the tribological mark 
used to describe the dependence of friction force on the sliding rate between two lubricated bodies [11-14].

Dry friction gives impacts on the performance of the machine in such a way that machine tasks are reduced or even crippled. Dry vibrations induced by friction (also known as stick-slip) cause problems of commotion, for example, bearing screech and jabber. Two segments of dry friction force create dry friction in mechanical contact between two strong bodies; forces of static and kinetic friction. The forces create a counterpart for the in-contact plane also limit the overall contact surfaces movement. Microscopic asperities in contact as forces of plastic, also elastic deformation, dry sliding friction can be demonstrated between two substrates $[15,16]$. Therefore, it is conceivable to control friction attributes through the use of reasonable surface film materials for the contacting bodies. In addition, the surface films may cause the consequence of sullying, oxidizing and removing the material. Mustafa [17] has created an impression with respect to an explanation of the occurrence of dry friction in composite materials. According to his job, it has been reported that the aim behind friction is cross-section vibration. Grid vibration occurs when strong surfaces are sliding as molecules of one surface cause other surface particles to vibrate. Some of the mechanical vitality is needed to move the two surfaces over one another will be converted into the warmth and sound waves.

The tribological cooperation of the uncovered face of a strong surface with interfacing materials and conditions can lead to material loss from the surface. At the atomic level, the crystal lattices of the two strong contact materials are in a balanced state $[18,19]$. At the point when a shear pressure is connected to one segment, the two cross-sections disfigure flexibly. On the off chance that the shear is additionally expanded and flimsiness is achieved, the iotas move to another situation of balance. The lattice of crystal vibrates until all the vitality of the strain is dispersed and all flexible vitality has been changed over to heat. At the moment the internal surfaces sliding over each other between two strong bodies, friction force, and frictional temperature were discovered to be increased. In this stage, no material exchanges from one surface to the next happens [20]. Just at the frictional most extreme, particles moved. At the point the exchange is started, the friction force diminishes to a sustained degree of stability. An exchange film is based on material characteristics and the growth to a particular thickness. For example, a homogeneous layer is not formed in a graphite-based composite. In any case, little graphite islands are formed. After the islands develop, the friction force decreases. At the moment when two sliding authoritative bodies of distinct composite materials oppose to each other, the harder material has found to have a contact layer on its outside. For example, heat and friction alter the features of surface materials. The friction layer is accountable for tribological features like the coefficient of friction, wear rate and vibration additional Raman spectroscopy examinations named after Sir C. V. Raman [21].

A sliding composite material has a surface layer on it. Frequently, the total synthesis of the softer material is not moved; however, just a portion of the synthetic segments. The two layers are administering the tribological attributes of sliding frameworks. The addition of synthetic parts to a sliding material is done and again to frame a specific rubbing layer to obtain the ideal tribological features. As a rule, dry friction procedure leads not to move but rather to material loss. This procedure is established as "wear". Real sorts of wear incorporate adhesion (friction), abrasion, corrosion, and erosion. Wear can be restricted by changing material characteristics or solid surface characteristics by "surface design" forms (usually referred to surface finishing) or using greases (for frictional or glue wear). Contingent upon operational parameters, for example, type of material, pressure and sliding speed, diverse frictional temperatures happen that offer ascent to different power misfortunes [22-24]. Dry friction consistently produces heat and thusly dispersion forms. Along these lines, dry sliding contact makes surface twisting resulting in a deformation of the crystal lattice and greater convergence of separations. Additionally, substance responses, for example, 
tribological oxidation and disintegrations, happen - every one of these variables at long last leads to fractures, cracks and wear. Depending on the load, rotational speed and viscosity, the operating point of a journal bearing can be located in a fluid, mixed, or boundary friction scheme [17]. Using a Stribeck curve, this relationship can be viewed as in Figure 2.

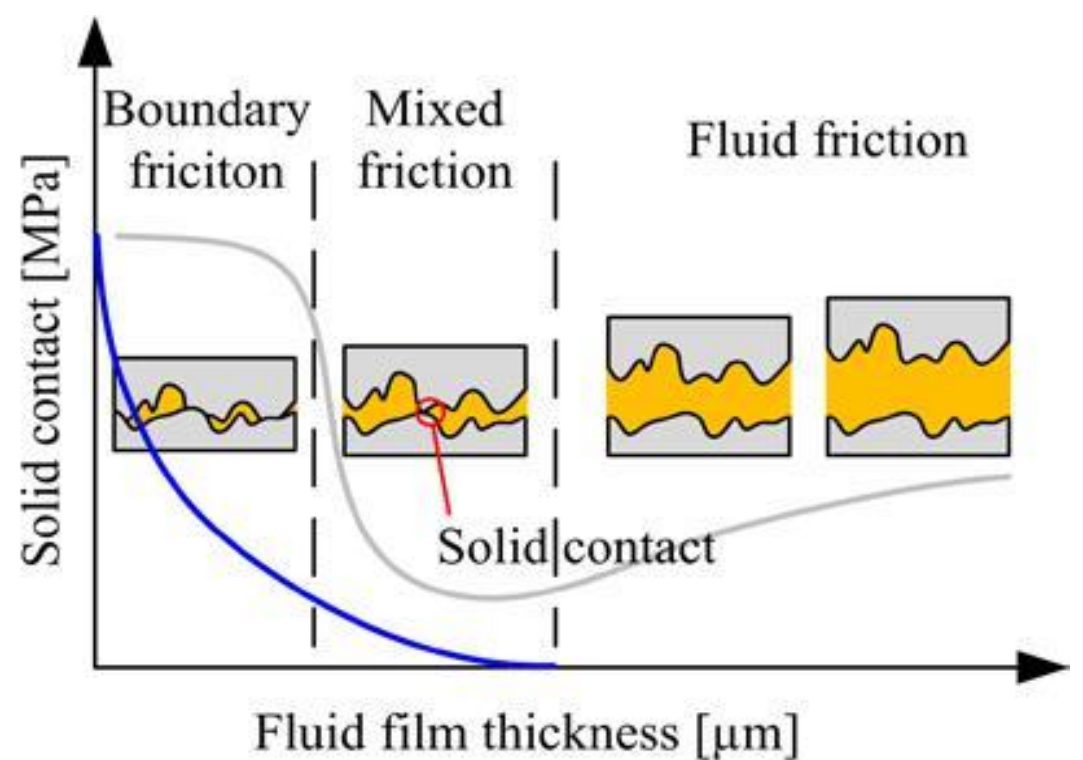

Fig. 2. Principle Stribeck curve [25]

\section{Wear}

The wear is the dynamic automatic expulsion of material with another or liquid from a surface in relative movement. Two different types of wear can be recognized: severe wear and mild wear. Smooth surfaces and low loads are the primary situations that need to be concerned, whereas notably heavier loads are also conforming and unpleasant surfaces, where wear procedures are noticeable. Wear takes on a primary job in tribological examinations as it may lead to changes in the state of the segments applied in, for instance, machinery construction. These ragged parts have to be supplanted, which involves an issue of monetary nature, because the expense of substitution, and a useful issue, since if these segments are not supplanted in time, progressively genuine harm could jump out at the machine in its complex [26]. This situation, be that as it may, not only has just negative sides, without a doubt, it is frequently used to reduce the unpleasantness of certain materials, disposing of the ill tempers. Mistakenly we will, in general, envision wear in an immediate relationship with friction, these two marvels cannot be effectively associated [15]. There might be conditions with the end goal that low friction can bring about huge wear or the other way around. This situation can happen, but particular usage times "are required, which may change depending on some variables, such as load, speed, lubrication, and environmental conditions, and there are different wear mechanisms, which may occur simultaneously or even combined with each other": a) adhesive wear, b) abrasive wear, c) fatigue wear, d) corrosive wear, e) fretting or rubbing wear, f) erosion wear, and lastly, g) other minor wear phenomena (cavitation, wear by impact, wearspreading, wear-fusion).

It is familiar that contact between two surfaces is happened by way of the collaboration between the bad temperatures. Because of it is bonded to the harder surface, it may be conceivable to limit a small piece of the stronger material on the off chance that shearing force used the contact area. This kind of wear is extremely dangerous because it involves high wear speeds and yet it is conceivable that the grip can be reduced by extending surface unpleasantness and also the hardness 
of the included materials or by embedding contaminant layers, for example, oxides, oxygen, oils or water. Taking everything into account, the conduct of the glue wear volume is depicted by methods for several principle laws. The emission of particles into the atmosphere is a significant element of wear that gradually affects human well-being and biology. Ernest Rabinowicz was the primary scholar who investigated until this point.

\section{Pin Wear Tester}

Pin wear tester is characterized as the science and innovation of interfacing surfaces in relative movement or at the end of the day, the investigation of friction, wear, and lubrication. From that point forward, the 'rubbing' between two surfaces has caused an upset. Today, this has turned into an undeniable part of science, presently known as pin wear tester. The pin disk wears tester combinations of the uncovered face of a powerful surface with interfacing components and the situation can result in material loss from the surface. The operation that causes material loss is referred as "wear." Real wear types are "friction (adherence and cohesion), abrasion, corrosion, and erosion. Alteration of the solids surface characteristics through one or more procedures of "surface engineering" (known as surface finishing) and the use of lubricants can minimize wear. On the other hand, one of the most important aspects of pin wear tester, and one that is still under investigation is generation of friction at atomic level [27]. The start of friction between two relatively moving surfaces is the way to find a reaction to the growing problem of tremendous budgetary misfortunes due to wear and friction. Friction is firmly identified with the vitality dispersal at the surface. At whatever point work is finished by a thermodynamic framework, heat is created, and this heat is equivalent to an adjustment in the internal energy of the framework in addition to the work done by the framework. This is known as the principal law of thermodynamics.

On account of friction, when outside work is finished by a frictional force, it ought to be equivalent to the vitality scattered in addition to the change in internal energy [28]. Pin wear tester portrayal is basic, particularly when they are proposed to diminish rubbing and decreased wear as to build life and execution of materials. This is especially significant in ventures such as aviation, tooling, car, and others where disappointment can be disastrous. Pin wear tester portrayal of wood coatings is basic when expected to guarantee wear obstruction parameters in the harsh conditions of wood items are found. Customarily wear, and friction testing has been performed with modest instrumentation giving little dependability. The immediate advantage in improving material surfaces pushes the requirement for good quantifiable testing. Other than that, unpleasant surfaces more often slow wear rate and have higher rubbing coefficients than smooth surfaces. Surface impacts are brought about by contrasts in surface harshness, microstructure, chemical composition, and residual stress. Furthermore, the laser-assisted turning (LAT) of silicon nitride ceramics production monetarily lessens the surface harshness and apparatus wear in contrast with just traditional turning process where the impact of connected stress and temperatures created at the front line and they were found to impact the wear rate and thus, the device life. The wear coefficient is extremely little (and increments just gradually with uprooting sufficiency) over the stick-slip system; at that point, it rises quickly with expanding dislodging adequacy. Worrying wear happens if two bodies are squeezed against one another and are in this way exposed to motions with little repetition. Regardless of whether there is no gross slip in the contact, digressive slip happens at the fringe of the contact territory prompting wear and fatigue. Fretting wear is one of a kind type of material debasement brought about by little abundancy oscillatory move relatively between surfaces in touch. Fretting wear is regularly experienced less than $300 \mathrm{~mm}$ removals either in a gross slip system (slip relocation occurs throughout the contact) or in a fractional slip system (portions of the contact which no slip 
uprooting happens) that further affected by the temperature of the slip. The corruption of surface and subsurface brought about by fretting is a mind-boggling procedure including friction, wear, plastic deformation, oxidation, and crack. At last, fretting maps can be a handy guide to fashioners and have been extended to cover different measurements (as opposed to only those of load and stroke which are most ordinarily utilized). "The pin-on-disk tribometer, shown in Figure 3, consists of a flat, pin, or sphere which is attached to a stiff elastic arm that is weighted down onto a test sample with a precisely known weight. The sample is rotated at a selected speed.

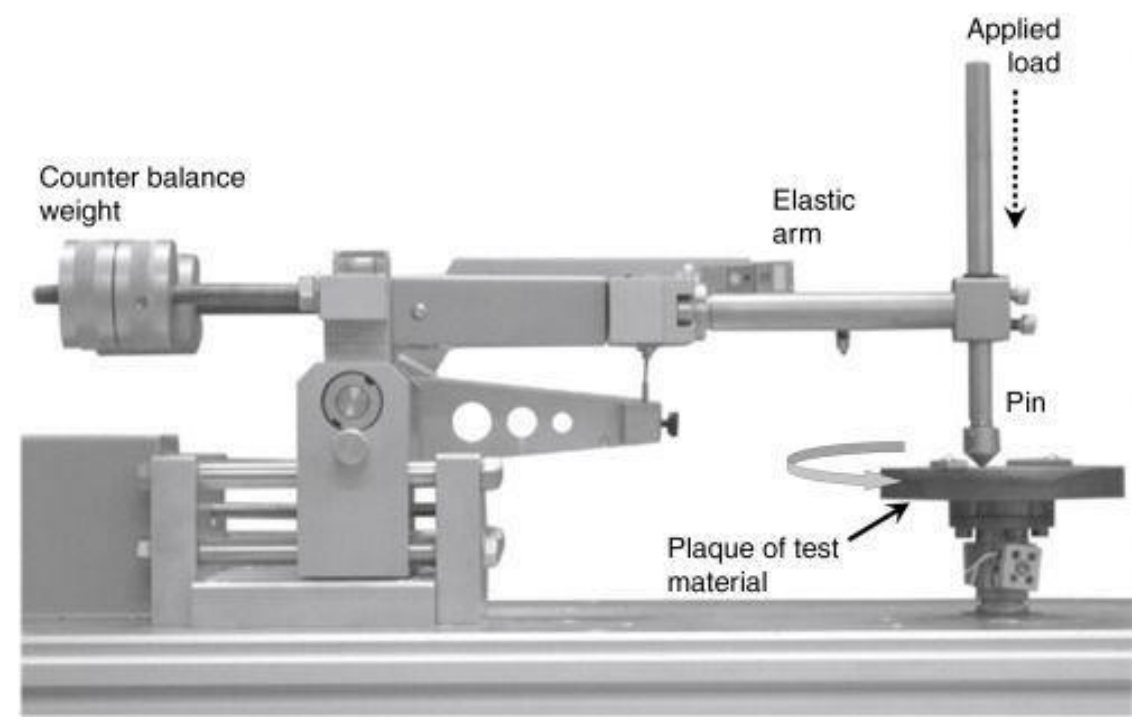

Fig. 3. Principle Stribeck curve [25]

\section{Conclusions}

This review explained well related to tribology on each fundamental of tribology such as friction, lubricants also wear. The main objective is on the saving of materials and energy, which can give good impact and enhance the quality of life and environment. This green tribology is an environmentally friendly tribology that highlights the elements of relatively moving surfaces that are crucial for energy or environmental sustainability [29-31].

\section{Acknowledgement}

The authors thanked the Ministry of Higher Education (MOHE) for financially supported this study through Fundamental Research Grant Scheme (FRGS/1/2018/TK10/UMP/02/1) - RDU190105, as well as Universiti Teknologi Malaysia (UTM) through Fundamental Research Grant Scheme (FRGS) funding number 5F188 and the Collaborative Research Grant (CRG) funding number 08G32.

\section{References}

[1] Vakis, A. I., V. A. Yastrebov, J. Scheibert, L. Nicola, D. Dini, C. Minfray, A. Almqvist et al. "Modeling and simulation in tribology across scales: An overview." Tribology International 125 (2018): 169-199. https://doi.org/10.1016/i.triboint.2018.02.005

[2] Ali, Imran, Anastasia Kucherova, Nariman Memetov, Tatiana Pasko, Kirill Ovchinnikov, Vladimir Pershin, Denis Kuznetsov, Evgeny Galunin, Vladimir Grachev, and Alexey Tkachev. "Advances in carbon nanomaterials as lubricants modifiers." Journal of Molecular Liquids 279 (2019): 251-266. https://doi.org/10.1016/i.molliq.2019.01.113

[3] Zhang, Shuai, Tianbao Ma, Ali Erdemir, and Qunyang Li. "Tribology of two-dimensional materials: From mechanisms to modulating strategies." Materials Today 26 (2019): 67-86. https://doi.org/10.1016/i.mattod.2018.12.002 
[4] Braun, O. M., and A. G. Naumovets. "Nanotribology: Microscopic mechanisms of friction." Surface Science Reports 60, no. 6-7 (2006): 79-158.

https://doi.org/10.1016/j.surfrep.2005.10.004

[5] Farfan-Cabrera, Leonardo Israel. "Tribology of electric vehicles: A review of critical components, current state and future improvement trends." Tribology International 138 (2019): 473-486. https://doi.org/10.1016/i.triboint.2019.06.029

[6] Pérez, A. Torres, G. García-Atance Fatjó, Mark Hadfield, and S. Austen. "A model of friction for a pin-on-disc configuration with imposed pin rotation." Mechanism and Machine Theory 46, no. 11 (2011): 1755-1772. https://doi.org/10.1016/i.mechmachtheory.2011.06.002

[7] Wahlström, Jens, D. Gventsadze, Lars Olander, E. Kutelia, L. Gventsadze, O. Tsurtsumia, and Ulf Olofsson. "A pinon-disc investigation of novel nanoporous composite-based and conventional brake pad materials focussing on airborne wear particles." Tribology international 44, no. 12 (2011): 1838-1843. https://doi.org/10.1016/j.triboint.2011.07.008

[8] Hussein, Adnan M., R. A. Bakar, and K. Kadirgama. "Study of forced convection nanofluid heat transfer in the automotive cooling system." Case Studies in Thermal Engineering 2 (2014): 50-61.

https://doi.org/10.1016/j.csite.2013.12.001

[9] Ambreen, Tehmina, and Man-Hoe Kim. "Heat transfer and pressure drop correlations of nanofluids: a state of art review." Renewable and Sustainable Energy Reviews 91 (2018): 564-583.

https://doi.org/10.1016/i.rser.2018.03.108

[10] Wahlström, Jens, Anders Söderberg, Lars Olander, Anders Jansson, and Ulf Olofsson. "A pin-on-disc simulation of airborne wear particles from disc brakes." Wear 268, no. 5-6 (2010): 763-769.

https://doi.org/10.1016/j.wear.2009.11.014

[11] Gnecco, Enrico, Roland Bennewitz, Oliver Pfeiffer, Anisoara Socoliuc, and Ernst Meyer. "Friction and Wear on the Atomic Scale." Nanotribology and Nanomechanics (2005): 483-533.

https://doi.org/10.1007/3-540-28248-3 10

[12] Rohatgi, Pradeep K., Meysam Tabandeh-Khorshid, Emad Omrani, Michael R. Lovell, and Pradeep L. Menezes. "Tribology of metal matrix composites." In Tribology for scientists and engineers, pp. 233-268. Springer, New York, NY, 2013.

https://doi.org/10.1007/978-1-4614-1945-7_8

[13] Maharaj, Dave, and Bharat Bhushan. "Friction, wear and mechanical behavior of nano-objects on the nanoscale." Materials Science and Engineering: R: Reports 95 (2015): 1-43.

https://doi.org/10.1016/j.mser.2015.07.001

[14] Menapace, Cinzia, Mara Leonardi, Guido Perricone, Mauro Bortolotti, Giovanni Straffelini, and Stefano Gialanella. "Pin-on-disc study of brake friction materials with ball-milled nanostructured components." Materials \& Design 115 (2017): 287-298.

https://doi.org/10.1016/j.matdes.2016.11.065

[15] Holmberg, Kenneth, Helena Ronkainen, and Allan Matthews. "Tribology of thin coatings." Ceramics International 26, no. 7 (2000): 787-795.

https://doi.org/10.1016/S0272-8842(00)00015-8

[16] Federici, Matteo, Mattia Alemani, Cinzia Menapace, Stefano Gialanella, Guido Perricone, and Giovanni Straffelini. "A critical comparison of dynamometer data with pin-on-disc data for the same two friction material pairs-A case study." Wear 424 (2019): 40-47.

https://doi.org/10.1016/i.wear.2019.02.009

[17] Aydin, Mustafa, and Fehim Findik. "Wear properties of magnesium matrix composites reinforced with SiO2 particles." Industrial Lubrication and Tribology 62, no. 4 (2010): 232-237.

https://doi.org/10.1108/00368791011051099

[18] Shi, L., Z. G. Guo, and W. M. Liu. "The recent progress of tribological biomaterials." Biosurface and biotribology 1 , no. 2 (2015): 81-97. https://doi.org/10.1016/j.bsbt.2015.06.002

[19] Spear, Jessica C., Bradley W. Ewers, and James D. Batteas. "2D-nanomaterials for controlling friction and wear at interfaces." Nano Today 10, no. 3 (2015): 301-314.

https://doi.org/10.1016/j.nantod.2015.04.003

[20] Chan, Chung-Hung, Sook Wah Tang, Noor Khairin Mohd, Wen Huei Lim, Shoot Kian Yeong, and Zainab Idris. "Tribological behavior of biolubricant base stocks and additives." Renewable and Sustainable Energy Reviews 93 (2018): 145-157. https://doi.org/10.1016/j.rser.2018.05.024

[21] Lelevic, Aleksandra, and Frank Walsh. "Electrodeposition of Ni-P composite coatings: a review surface and coatings 
technology." Surface and Coatings Technology (2019): 1-80.

https://doi.org/10.1016/i.surfcoat.2019.07.027

[22] Czichos, Horst. "Review on wear research-activities in the FRG." Wear 100, no. 1-3 (1984): 579-589.

https://doi.org/10.1016/0043-1648(84)90034-6

[23] Van Groenou, A. Broese. "Tribology of magnetic storage systems, a short review." Journal of magnetism and magnetic materials 95, no. 3 (1991): 289-312. https://doi.org/10.1016/0304-8853(91)90226-Z

[24] Zhai, Wenzheng, Narasimalu Srikanth, Ling Bing Kong, and Kun Zhou. "Carbon nanomaterials in tribology." Carbon 119 (2017): 150-171.

https://doi.org/10.1016/i.carbon.2017.04.027

[25] Bergmann, P., and F. Grün. "Modeling Wear of Journal Bearings." In COMSOL Conference. 2016.

[26] Donnet, C. "Recent progress on the tribology of doped diamond-like and carbon alloy coatings: a review." Surface and Coatings Technology 100 (1998): 180-186. https://doi.org/10.1016/S0257-8972(97)00611-7

[27] Allen, C., and A. Ball. "A review of the performance of engineering materials under prevalent tribological and wear situations in South African industries." Tribology International 29, no. 2 (1996): 105-116.

https://doi.org/10.1016/0301-679X(95)00073-D

[28] Kumar, B. Satheesh, G. Padmanabhan, and P. Vamsi Krishna. "Performance assessment of vegetable oil based cutting fluids with extreme pressure additive in machining." J. Adv. Res. Mater. Sci. 19, no. 1 (2016): 1-13.

[29] Sazali, N., W. N. W. Salleh, A. F. Ismail, N. H. Ismail, Mohamad Azuwa Mohamed, N. A. H. M. Nordin, M. N. M. M. Sokri, Y. Iwamoto, and S. Honda. "Enhanced gas separation performance using carbon membranes containing nanocrystalline cellulose and BTDA-TDI/MDI polyimide." Chemical Engineering Research and Design 140 (2018): 221-228.

https://doi.org/10.1016/i.cherd.2018.09.039

[30] Ismail, Nor Hafiza, Wan Norharyati Wan Salleh, Norazlianie Sazali, and Ahmad Fauzi Ismail. "The effect of polymer composition on $\mathrm{CO} 2 / \mathrm{CH} 4$ separation of supported carbon membrane." Chemical Engineering Transactions 45 (2015): 1465-1470.

[31] Sazali, N., W. N. W. Salleh, A. F. Ismail, N. H. Ismail, F. Aziz, N. Yusof, and H. Hasbullah. "Effect of stabilization temperature during pyrolysis process of P84 co-polyimide-based tubular carbon membrane for H2/N2 and He/N2 separations." In IOP Conference Series: Materials Science and Engineering, vol. 342, no. 1, p. 012027. IOP Publishing, 2018.

https://doi.org/10.1088/1757-899X/342/1/012027 